\title{
Biogas: tratamiento de efluentes para el saneamiento ambiental en tambos y corrales
}

Virginia Monzón'; Daniel Machuca; Noemí Sogari²; Griselda Medina ${ }^{3}$; Eduardo Ricciardi (*)

\section{RESUMEN:}

Investigadores y alumnos de G.I.E.S.M.A de la Fa.Ce.Na de la UNNE llevan a cabo un trabajo de investigación que procura poner en funcionamiento eficiente un dispositivo (biodigestor) económico para ser aprovechado por productores agropecuarios para generar biogás a partir del tratamiento de efluentes agrarios, como una alternativa para dar solución a una problemática energética y socio-ambiental fomentando el uso de las energías renovables. Se trabaja con un tanque de agua de 200 litros de capacidad adaptado al funcionamiento de un digestor de carga semicontinua donde se lleva a cabo el seguimiento de diferentes parámetros físicos y químicos que ocurren durante el proceso de degradación de desechos agro productivo. El sistema de adquisición de datos tiene como objetivo monitorear las condiciones en las que trabajan las bacterias y los microorganismos involucrados en generación del biogás, a partir de esto, modificar las magnitudes y llevar a su punto óptimo el funcionamiento de manera automatizada y generar energía.

Palabras Claves: Biodigestor-Sistematización-Monitoreo

\section{Abstract:}

Researchers and students of GIESMA of the Fa.Ce.Na of the UNNE carry out a research work that seeks to put into efficient operation an economic device (biodigester) to be used by agricultural producers to generate biogas from the treatment of agricultural effuents, as an alternative to solve an energy and socio-environmental problem fostering the use of renewable

(*) Grupo de Investigación de las Energías Sustentables y del Medio Ambiente. Facultad de Ciencias Exactas y Naturales y Agrimensura. Universidad Nacional del Nordeste (UNNE).

${ }^{1}$ Becaria EVC Fa.CE.NA UNNE 2018 Resol N¹80018. virgmonzon@gmail.com

${ }^{2}$ Directora del proyecto financiado por SGCYT de la UNNE PI17F015.noemisogari@gmail.com

${ }^{3}$ Pasante no rentado en el PI17F015 Resol N¹01718 CD Fa.CE.NA.gri3783@gmail.com 
energies. We work with a water tank of 200 liters of capacity adapted to the operation of a semi-continuous charge digester where the monitoring of different physical and chemical parameters that occur during the degradation process of agro productive wastes is carried out. The objective of the data acquisition system is to monitor the conditions in which the bacteria and microorganisms involved in the generation of the biogas work, from this, to modify the magnitudes and to bring their functioning to an optimum level in an automated way and generate energy.

Keywords: Biodigester-Systematization-Monitoring

\section{INTRODUCCIÓN:}

Para reducir el impacto ambiental de procesos agrícolas y abastecer el consumo interno de energía, podemos recurrir a la degradación anaeróbicas de residuos orgánicos, lo que además de ser una solución para un problema ambiental, también genera biofertilizante de excelente calidad. La descomposición anaeróbica de sustancias orgánicas encontradas en vertederos de efluentes de industrias, tambos, criaderos originan el denominado gas de los pantanos que causa el calentamiento global si se le permite escapar a la atmósfera (Ahmed S.I. et al 2015). Es por ello que el tratamiento de efluentes agrícola y ganaderos, donde se lleva a cabo la cría de animales y/o emprendimientos agro productivos se presenta como una alternativa simple, fácil de operar y sobre todo de bajo costo para su implementación y generación de energía
(Monzón V. et al 2018)2. El objetivo del trabajo es producir biogás a partir de la fermentación de la materia orgánica existente en efluentes de tambos y emprendimientos agrícolas, como una alternativa para dar solución a un problema energético y socioambiental. La biodigestión anaeróbica, es un proceso de fermentación natural llevado a cabo por microorganismos en ausencia de oxígeno, que se encuentra favorecido por varios factores como ser temperatura, $\mathrm{pH}$, materia orgánica y contenido de agua en la biomasa, entre otros (Gropelli, E. 2001). E1 uso de digestores anaeróbicos para el procesamiento de los desechos agrícolas y ganaderos, tiene múltiples beneficios además de la obtención de energía, la disminución de costos en energía eléctrica, reducción de olores y contaminación de aguas superficiales y subterráneas y luego como producto final de la digestión la generación de fertilizante de alta calidad, llamado biol. En el proceso, el gas metano puede ser recogido, tratado y utilizado para la generación de electricidad o actualizado a hogares, edificios y vehículos eléctricos. Aprovechar la biomasa proveniente de efluentes es una actividad de energía renovable que contribuye minimizar el impacto ambiental.

\section{METODOLOGÍA}

Se utilizó en el proyecto un tanque de agua de 200 litros de capacidad adaptado a un biodigestor de carga semicontinua. E1 uso de este tipo de tanque presenta beneficios para ser usado por el sector rural debido a su bajo costo respecto de los sistema e instalación de digestores comerciales; así 
como la flexibilidad del material a la hora de hacerle las modificaciones pertinentes al proyecto en cuestión.

El digestor se encuentra compuesto por: tubo de entrada de la materia orgánica, cámara de fermentación, cámara de depósito de gas, cámara de salida de efluente, conducto de gas, tapa hermética. Para monitorear el funcionamiento del sistema se instalaron sensores de temperatura, humedad, nivel de biomasa, cantidad de metano que se encuentran conectados a un sistema de control. El sistema contempla dos funciones; una de ellas es monitorear las distintas magnitudes mediante sensores distribuidos en su mayoría dentro del reactor. Algunos sensores, como el de la temperatura, se encuentran sumergidos en la biomasa. Mientras que otras se encuentran en lugares estratégicos dentro del reactor, como el sensor de detección de gas metano, el cual está ubicado en la parte superior. Además, el sistema consta de sensores que están instalados en el exterior para medir los parámetros del ambiente y así comparar estos datos con los obtenidos en el interior del digestor. En segundo término, el sistema de control permite que a partir de los datos recabados se logre una automatización en el funcionamiento, ejecutando acciones como ser la apertura de una válvula para la liberación de gases no deseados o encender un motor que ponga un funcionamiento un agitador para la biomasa. Los sensores y válvulas mencionadas antes están manejadas por un micro controlador (ATMEL), en el cual la programación nos permitirá ver los valores arrojados en un display y comparar, de ser necesario, los valores que sean óptimos para la digestión y así realizar las acciones pertinentes.

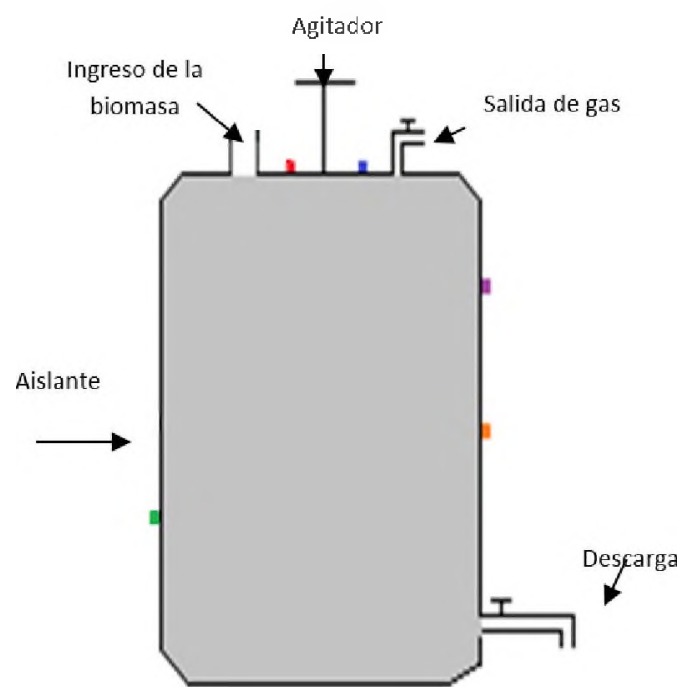

Sensor de temperatura y humedad ambiente.

Sensor de metano.

Sensor de presión.

Sensor de nivel de la biomasa.

Sensor de temperatura de la biomasa.

Figura 1: Esquema ilustrativo del sistema de adquisición de datos 
En el caso de nuestro proyecto, la carga óptima con la que se trabajó, fue de dos terceras partes del biodigestor, queriendo colocar un gasógeno, en una segunda etapa, para poder recoger el gas obtenido y usarlo como combustible. La suspensión dentro del reactor está formada por estiércol de vaca y agua. Durante el desarrollo de la experiencia con el digestor se suscitaron pérdidas ocasionadas al principio de la construcción, debido a que no son totalmente herméticos, y a consecuencia también de las perforaciones realizadas en la construcción del digestor en cuestión, inconvenientes que hemos ido solucionando a medida que se presentaban. Otra desventaja que presenta el material empleado, es la dificultad de mantener la temperatura requerida en el interior para realizar el proceso de biodigestión, ante las bajas temperaturas en temporadas invernales, lo cual ralentiza o detiene el proceso.

\section{RESULTADOS Y DISCUSIÓN}

Para llevar a cabo la experiencia se trabajó en dos etapas, primero se armó el equipo buscando materiales que sean adecuados para el ensayo y se procedió a cargar el equipo con una cierta cantidad de inóculo inicial de manera de ir caracterizando y mejorando el funcionamiento del reactor. Se puedo recolectar datos útiles mediante los análisis desarrollados en el laboratorio que involucran los siguientes parámetros químicos fundamentales para el monitoreo continuo: Sólidos Totales (ST), Sólidos Volátiles (SV) y Demanda Química de Oxígeno (DQO)-

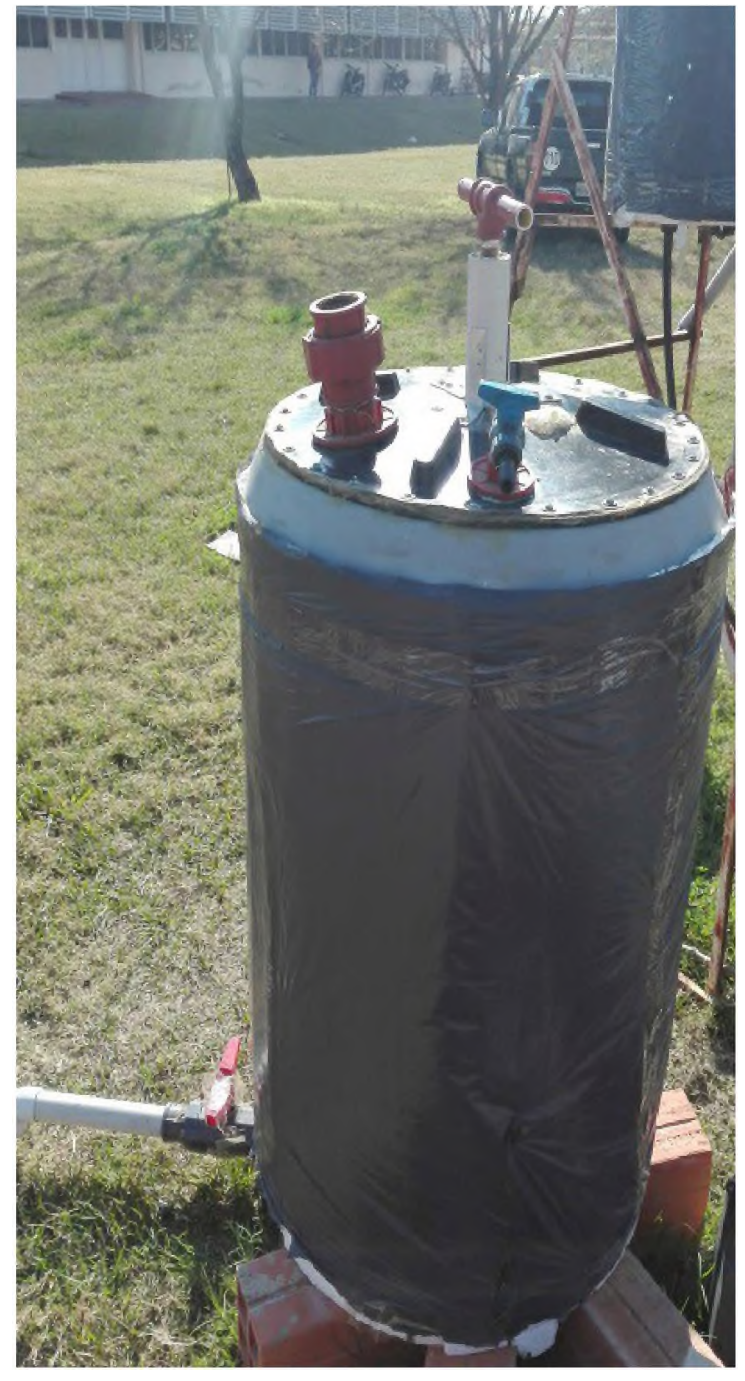

Figura 2: Sistema experimental de biodigestion de flujo semicontinuo

A continuación, se evidencia los resultados obtenidos en diferentes periodos de tiempo, donde las respectivas muestras fueron tomadas cada 22 días con un tiempo de retención inicial de 50 días (ver figura 3).

Los resultados obtenidos, proporcionan información respecto al progreso de la digestión que transcurre en el interior del reactor, lo cual nos permitió corroborar que el 


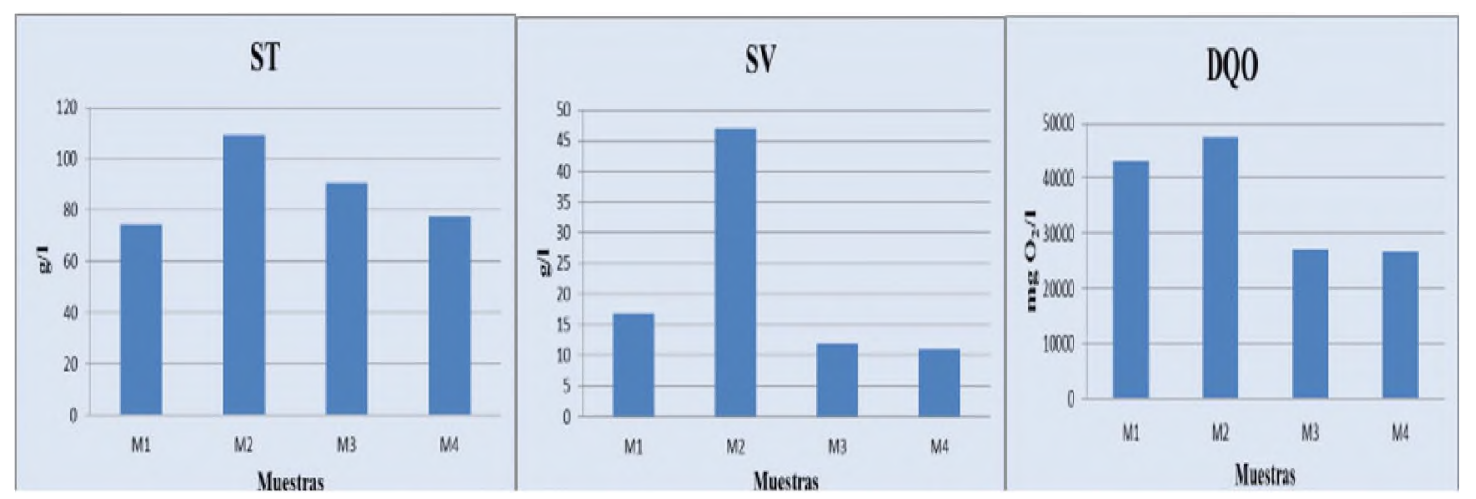

Figura 3: Variación de $S T, S V$ y $D Q O$ en diferentes muestras del mismo reactor

proceso de fermentación ocurría según lo con la temperatura y humedad ambiente, previsto y ajustar las proporciones de inó- como así también la presencia de metano culos que dan mejores resultados. Antes de en el reactor. Cada uno de estos parámetomar la muestra 2, se re inoculó al reactor tros converge en el estudio de los distintos para mejorar producción de metano.

condicionantes y factores que participan en el proceso para garantizar la viabilidad

Mediante la utilización de sensores ubicados estratégicamente se pudo medir del biodigestor, que inciden en la producla temperatura de la biomasa y compararla ción de biogás. La disminución de dichos
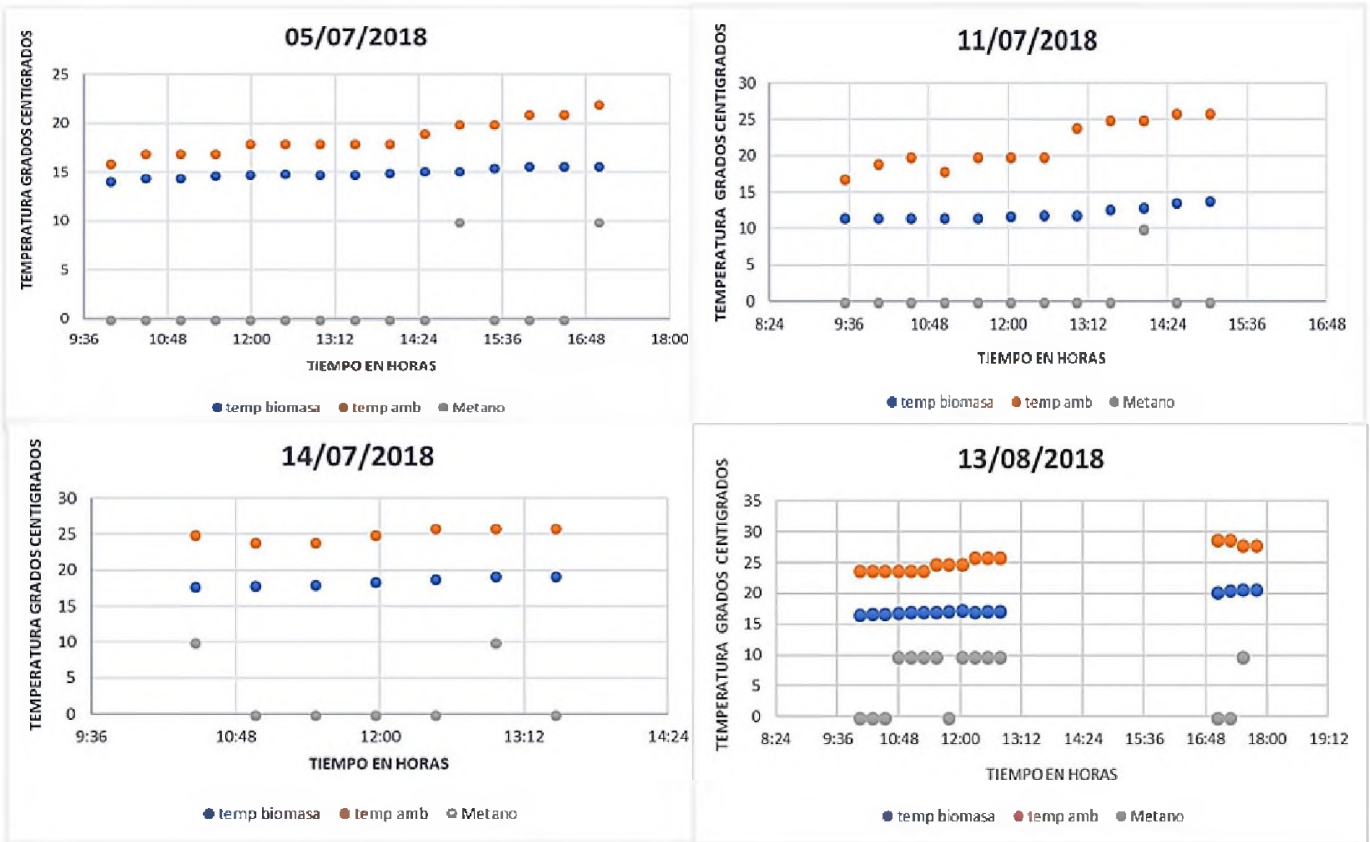

Figura 4: Gráficas de variación diaria de temperatura de la biomasa, temperatura ambiente y presencia de metano en función del tiempo. 
parámetros involucra una reducción de la materia orgánica incorporada en el reactor, efecto que procede como consecuencia del aumento en la producción de metano como producto final de la fermentación anaeróbica.

\section{CONCLUSIÓN}

El fácil acceso a las energías renovables del sector rural, así como el cuidado del medio ambiente es el fin de este proyecto de investigación. Durante el desarrollo del mismo se presentaron varios inconvenientes, lo cuales muchos de ellos pudimos solucionar y otros estamos en vía a encontrar una respuesta alternativa para poder optimizar el funcionamiento del biodigestor. Se espera aún optimizar el sistema, a los efectos de adaptar convenientemente, un tanque de agua a un fermentador anaeróbico que genere suficiente biocombustible para utilizarlo como energía térmica y eléctrica. Como indican algunas fuentes bibliográficas con una carga de $140 \mathrm{~kg}$ de sustrato orgánico unos 28 metros cúbicos de biogás a la temperatura entre 20 y $25{ }^{\circ} \mathrm{C}$, lo cual permitirá hervir 267 litros de agua.

\section{AGRADECIMIENTOS:}

Deseamos manifestar nuestro más sincero agradecimiento al Licenciado. Juan Daniel Ruiz Días por habernos propiciado el espacio de LABQUIAM para poder realizar los análisis químicos pertinentes en el laboratorio, así como su paciencia, capacidad y colaboración en la formación de las alumnas de la UNNE.

\section{BIBLIOGRAFÍA}

1. Gropelli, Eduardo s. y Giampaoli Orlando a. (2001). El camino de la biodigestión. Ambiente y tecnología socialmente apropiada. 2001.

2. Monzón, V; Mena, C; Sogari,N. Biogás: Una alternativa sustentable para su implementación en laboratorios escolares rurales. Revista Extensión, Innovación y Transferencia tecnológica.ISSN, 2422-6424,4:352357.2018.

3. Sogari N. (2012) Análisis de las propiedades físico químicas del biogas obtenido de la degradación anaeróbica de residuos orgánicos. AVERMA. Vol 16. ISSN: 0329-5184.- 